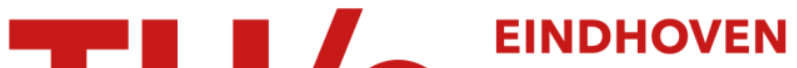 \\ UNIVERSITY OF \\ TECHNOLOGY
}

\section{Plasma deposited carbon films as a possible means for divertor repair}

Citation for published version (APA):

Buuron, A. J. M., Beulens, J. J., Groot, P., Bakker, J., \& Schram, D. C. (1992). Plasma deposited carbon films as a possible means for divertor repair. Thin Solid Films, 212(1-2), 282-295. https://doi.org/10.1016/00406090(92)90534-I

DOI:

10.1016/0040-6090(92)90534-I

Document status and date:

Published: 01/01/1992

\section{Document Version:}

Publisher's PDF, also known as Version of Record (includes final page, issue and volume numbers)

\section{Please check the document version of this publication:}

- A submitted manuscript is the version of the article upon submission and before peer-review. There can be important differences between the submitted version and the official published version of record. People interested in the research are advised to contact the author for the final version of the publication, or visit the $\mathrm{DOI}$ to the publisher's website.

- The final author version and the galley proof are versions of the publication after peer review.

- The final published version features the final layout of the paper including the volume, issue and page numbers.

Link to publication

\section{General rights}

Copyright and moral rights for the publications made accessible in the public portal are retained by the authors and/or other copyright owners and it is a condition of accessing publications that users recognise and abide by the legal requirements associated with these rights.

- Users may download and print one copy of any publication from the public portal for the purpose of private study or research.

- You may not further distribute the material or use it for any profit-making activity or commercial gain

- You may freely distribute the URL identifying the publication in the public portal.

If the publication is distributed under the terms of Article 25fa of the Dutch Copyright Act, indicated by the "Taverne" license above, please follow below link for the End User Agreement:

www.tue.nl/taverne

Take down policy

If you believe that this document breaches copyright please contact us at:

openaccess@tue.nl

providing details and we will investigate your claim. 


\title{
Plasma deposited carbon films as a possible means for divertor repair
}

\author{
A. J. M. Buuron and J. J. Beulens \\ Department of Physics, Eindhoven University of Technology, P.O. Box 513, 5600 MB Eindhoven (The Netherlands) \\ P. Groot and J. Bakker \\ Netherlands Energy Research Foundation, ECN, P.O. Box 1, 1755 ZG Petten (The Netherlands) \\ D. C. Schram \\ Department of Physics, Eindhoven University of Technology, P.O. Box 513, 5600 MB Eindhoven (The Netherlands)
}

(Received August 16, 1991)

\begin{abstract}
Fast deposition of graphitic carbon layers by an expanding cascaded arc plasma was studied as a means for in situ repair of graphite erosion damage in the next step fusion reactor NET/ITER. Amorphous graphite was produced at rates of hundreds of nanometers per second on several square centimeters with an argon-hydrocarbon plasma. Crystalline graphite was produced at rates of $10-50 \mathrm{~nm} \mathrm{~s}^{-1}$ on several square centimeters by means of an argon-hydrogen-hydrocarbon plasma. Relations between the deposition parameters, morphology (from scanning electron microscopy) and Raman spectra were determined. Using laser thermal shock testing, the erosion resistances of the best crystalline coatings were determined at about $2 \mathrm{MJ} \mathrm{m}^{-2}$ (in a $10 \mathrm{~ms}$ pulse).
\end{abstract}

\section{Introduction}

In the next step fusion device NET/ITER the surface armor for the plasma-facing components is a critical issue. Disruption erosion, particularly on the divertor plates, is a primary lifetime determining factor. One of the best engineering solutions is coating the divertor plates with carbon-based materials, either with highly oriented pyrolytic graphite (HOPG) or carbon fiber composite (CFC). The erosion of a carbon divertor is estimated as a total of $50 \mathrm{~kg}$ material loss per disruption event [1]. This would necessitate frequent shutdown of the machine for replacement of the plates. Performing this by remote handling techniques would require months. In situ repair methods are under investigation as an alternative solution.

Eindhoven University of Technology, The Netherlands Energy Research Foundation (Petten ECN) and the Next European Torus (NET) team are cooporating in the study of fast carbon deposition by an expanding cascaded arc as an option for in situ repair of erosion damage. With this particular deposition method, in the past deposition rates of up to $200 \mathrm{~nm} \mathrm{~s}^{-1}$ for a-C:H (amorphous hydrogenated carbon) [2] and of up to $10 \mathrm{~nm} \mathrm{~s}^{-1}$ for diamond films [3] have been obtained. These rates are an order of magnitude higher than those with the conventional r.f. or d.c. glow discharge methods.

For the present purpose, attention was focused on the deposition of graphitic carbon. In a feasibility study the possibility of very fast deposition of nanocrystalline ("amorphous") graphite at hundreds of nanometers per second by an argon-hydrocarbon plasma has been demonstrated [4]. The microstructure of the coatings was analyzed by scanning electron microscopy (SEM) and Raman spectroscopy. At the Netherlands Energy Research Foundation, ECN, disruption simulation experiments with a laser thermal shock set-up [5] were carried out. It appeared that the amorphous graphite coatings cannot sustain a thermal shock of $4 \mathrm{MJ} \mathrm{m}^{-2}$ in $10 \mathrm{~ms}$ (a lower limit for the disruption energy dump).

In an extensive second stage of the project the crystallinity of the graphite was optimized. To this end hydrogen was admixed in the argon-hydrocarbon plasma while other parameters were also varied. In this study direct relations between morphology (from SEM), Raman spectra and thermal shock (erosion) resistance of the coatings on the one hand and the reactor parameters during deposition on the other hand were demonstrated. Interrelations between the results of the three diagnostics are also shown.

\section{Design of the next step fusion reactors}

In Fig. 1 an outline of the design of ITER, the International Thermonuclear Experimental Reactor, is shown [6]. It is designed to operate in a double null separatrix configuration with divertor plates. By virtual 


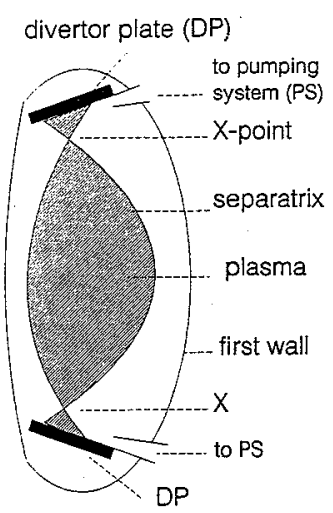

Fig. 1. Outline of ITER design with the divertor plates.

crossings of the magnetic field lines (the $\mathrm{X}$-points), the fusion product helium, impurities and thermal power are diverted from the plasma edge toward the plates. After neutralization the particles are abducted by the torus vacuum pumping system. A relevant feature of the machine with respect to maintenance is the giant dimensions. The torus center radius is $5.8 \mathrm{~m}$. The required divertor plate area is about $200 \mathrm{~m}^{2}$.

The choice of materials for the plasma-facing components, divertor plates and first wall, is a critical issue. The divertor plates, particularly, are subjected to high heat loads and particle fluxes. The principal requirements for surface armor material can be summarized as follows: a low atomic number $Z$; a high thermal conductivity and a high thermal shock resistance; a dense structure to minimize the tritium retention.

We will summarize the estimated performance data of carbon as a surface armor material $[1,5,6]$. Compression annealed pyrolytic graphite (CAPG) and carbon fiber composites (CFC) in particular are considered as suitable materials. In the most recent design [6] the latter were selected primarily because of their unique thermal shock resistance and the potential for tailoring them to specific other requirements such as a high thermal conductivity.

During normal operation the divertor plates will have to accommodate an average heat flux of $0.6 \mathrm{MW} \mathrm{m}^{-2}$, with static peak surface heat fluxes of $15-30 \mathrm{MW} \mathrm{m}^{-2}$. In addition the surface will suffer from an average neutron wall load of $0.5 \mathrm{MW} \mathrm{m}^{-2}$, and a DT-ion peak flux of $4 \times 10^{23} \mathrm{~m}^{-2} \mathrm{~s}^{-1}$ (energy $50-100 \mathrm{eV}$ ). The surface temperature of the carbon divertor armor has to be controlled to maximally around $1000^{\circ} \mathrm{C}$ in order to limit "run-away" erosion by self sputtering.

Estimates for the energy deposition on the divertor plates in a disruption are $10-20 \mathrm{MJ} \mathrm{m}^{-2}$ in $0.1-3 \mathrm{~ms}$ (in the thermal quench) and $2 \mathrm{MJ} \mathrm{m}^{-2}$ in $5-50 \mathrm{~ms}$ (in the consequent current quench).

In one of the main design options [1] the divertor armor will consist of 500000 replaceable carbon tiles brazed to a metallic alloy as a heat sink. In the case of a full power disruption, the material loss is predicted to be $50 \mathrm{~kg}$ of carbon, equivalent to a damage track of approximately $0.7 \mathrm{~mm}$ depth over a total area of approximately $3.6 \mathrm{~m}^{2}$. The thickness of the armor is limited by its maximally allowable surface temperature of $1000^{\circ} \mathrm{C}$, and thus by its thermal conductivity. For $\mathrm{CFC} /$ graphite the maximum is about $1 \mathrm{~cm}$, which limits the allowable number of disruptions per plate to $8-12$. The local erosion can be reduced by sweeping the $X$-points of the separatrix (by values of the order of $\pm 10 \mathrm{~cm}$ and at $0.1 \mathrm{~Hz}$ ), reducing the number of necessary replacements. An estimated minimum of 100 disruptions in the first operation phase ("physics" phase) would still imply a number of divertor plate replacements of 6-10. In an alternative calculation [6] a number of 9-17 replacements is obtained (see also ref. 5 of this issue). Considering the estimate that each replacement will require 3-6 months, the need for an effective in situ repair method is obvious. The in situ deposited material should approach the specifications summarized above. An additional requirement is an adequately high deposition rate. The feasibility of achieving high carbon deposition rates with the expanding cascaded arc technique has already been reported in ref. 4 . The present study was primarily focused on depositing (crystalline) coatings with good thermal shock resistance, while retaining a reasonably high growth rate.

\section{Carbon deposition by an expanding cascaded arc plasma}

\subsection{The expanding cascaded arc set-up}

In Fig. 2 an outline of the expanding cascaded arc set-up for carbon deposition is shown. The main feature of the method is the separation of the three functions production, transport, and deposition. The principal advantages of this method compared with conventional methods are high growth rates by the active particle transport towards the substrate, and flexibility in handling arc and substrate parameters. A cascaded arc plasma (4 mm diameter, $6 \mathrm{~cm}$ length), expanding in a vacuum chamber is used as a particle source. Specific features of this source are a high power dissipation (approximately $5 \mathrm{~kW}$ ), a thermal plasma (temperatures of approximately $1 \mathrm{eV}$ ) and very long times of continuous operation (days). The carrier gas argon is injected at the beginning of the arc channel at a flow rate of 100 standard $\mathrm{cm}^{3} \mathrm{~s}^{-1}$, which means a flow rate of $100 \mathrm{~cm}^{3} \mathrm{~s}^{-1}$ normalized on a pressure of $10^{5} \mathrm{~Pa}$. The inlet pressure is of the order of $5 \times 10^{4} \mathrm{~Pa}$. The ionization degree is typically about $10 \%$, rendering an electron density of the order of $10^{22} \mathrm{~m}^{-3}$. As a consequence 


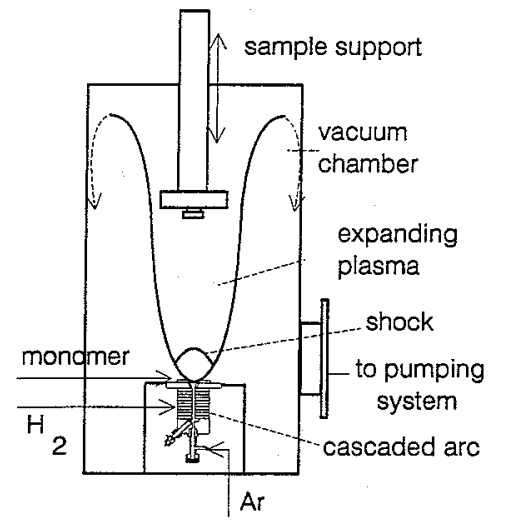

Fig. 2. The expanding cascaded arc set-up for deposition.

the arc plasma is close to the local thermal equilibrium (LTE). A hydrocarbon $\left(\mathrm{CH}_{4}\right.$ or $\left.\mathrm{C}_{2} \mathrm{H}_{2}\right)$ can be injected (at rates of $0-10$ standard $\mathrm{cm}^{3} \mathrm{~s}^{-1}$ ) at the end of the arc channel. Hydrogen can be admixed as an etching agent in the middle of the channel. By dissociation and charge exchange a beam of excited species, radicals and ions ( $\mathrm{Ar}, \mathrm{C}, \mathrm{H}, \mathrm{C}_{x} \mathrm{H}_{y}$ ) is created, expanding out of the end of the arc channel (the nozzle). The particles are accelerated to supersonic velocities of up to about $4000 \mathrm{~m} \mathrm{~s}^{-1}$, pass through a shock and are transported further towards a substrate at subsonic velocities, decreasing down to a few hundreds of meters per second. A typical value for the chamber pressure is $10^{2} \mathrm{~Pa}$ (for $\mathrm{a}-\mathrm{C}: \mathrm{H}$ deposition); in this case the shock can be observed at about $4 \mathrm{~cm}$ from the nozzle. Beyond the shock, the total energy of the species decreases to typically about $0.5 \mathrm{eV}$. A typical value for the carbon ion flux is $10^{19} \mathrm{~s}^{-1}$. The total transport time of all particles is relatively small (of the order of $10^{-4}$ $10^{-3} \mathrm{~s}$, the radiative recombination is negligible, the loss of ionization by three particle recombination is less than $1 \%[7]$.

An important aspect in the present framework is the radial expansion of the beam, which is governed by diffusion. From Fig. 3 we can deduce that the beam cross-section area $A_{\mathrm{b}}$ is approximately linearly proportional to distance to the nozzle $d_{n-s}$, and reciprocal to

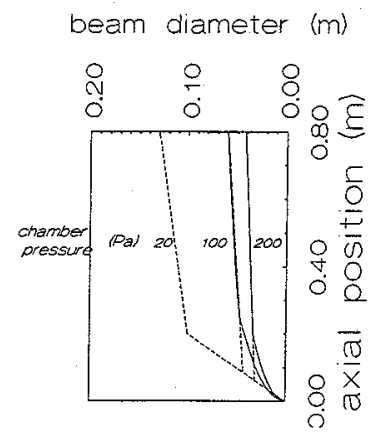

Fig. 3. Measured ( - ) and calculated $(---)$ beam profiles in the expansion (from ref. 8). the chamber pressure $p_{\mathrm{c}}$. For instance, for a-C:H deposition with $d_{\mathrm{n}-\mathrm{s}}=80 \mathrm{~cm}$ and $p_{\mathrm{c}}=20 \mathrm{~Pa}, A_{\mathrm{b}}$ is approximately $120 \mathrm{~cm}^{2}$. Extrapolating, for all values of chamber pressures, we can calculate the beam cross-section area by dividing the area at $p_{c}=1$ mbar $\left(10^{2} \mathrm{~Pa}\right)$ by $p_{\mathrm{c}}$ (expressed in millibars). In a similar way the beam cross-section areas for various nozzle to substrate distances can be deduced linearly from the value at one specific $d_{\mathrm{n}-\mathrm{s}}$. We define a normalized deposition rate $R_{\mathrm{n}}$ as a measure of the volume deposition rate by dividing the linear deposition rates by $p_{\mathrm{c}}: R_{\mathrm{n}}=R_{\mathrm{d}} / p_{\mathrm{c}}$. More details on the reactor and the cascaded arc can be found elsewhere $[2,3,4,8,9]$.

\subsection{Deposition conditions and materials}

By varying the reactor parameters, the type, quality and growth rate of the films can be modified. As reported in ref. 4 , the (linear) deposition rate $R_{\mathrm{d}}$ is a function of all reactor parameters: the arc power $P_{\text {arce }}$, the gas flow rates (\{argon\}, \{hydrocarbon\}, \{hydrogen\}), the type of hydrocarbon (monomer) feed gas, the number of carbon atoms in relation to the arc power (expressed by an inverse energy factor $Q$ ), the chamber pressure $p_{c}$, the deposition temperature $T_{\mathrm{s}}$ and the nozzle to substrate distance $d_{\mathrm{n}-\mathrm{s}}$. In ref. 4 a survey of reactor settings for different materials can be found. For the actual goal of crystalline graphite deposition the following considerations have been taken into account.

(1) For the specified purpose, a coating without hydrogen and weakly bonded carbon is required. This can be done by increasing the hydrogen admixture in the plasma while reducing the nozzle to substrate distance and increasing the chamber pressure. At a nozzle-substrate distance of $20 \mathrm{~cm}$ the addition of a moderate amount of hydrogen in the plasma leads to etching of the CFC substrates [4]. Currently, for most trials a nozzle-sample distance of $5 \mathrm{~cm}$ has been applied (unless indicated otherwise).

(2) A high deposition temperature, of at least $600^{\circ} \mathrm{C}$, to avoid hydrogen incorporation [10], and probably even greater than $900^{\circ} \mathrm{C}$ [11] to favor crystallization, is required.

(3) For high rate graphite deposition, acetylene $\left(\mathrm{C}_{2} \mathrm{H}_{2}\right)$ is more efficient than methane $\left(\mathrm{CH}_{4}\right)$, with and without hydrogen addition [4]. This choice is also indicated by others. The $\mathrm{C}_{2}$ radicals play an important role [12].

Taking into account these data, the properties of the deposited graphite have been studied primarily in relation to the following three main deposition conditions:

(1) the hydrogen admixture flow rate $\{\mathrm{H}\}$, mostly expressed in relation to the carbon flux in the expanding beam

$\{\mathrm{H}\} /\{\mathrm{C}\}$ 


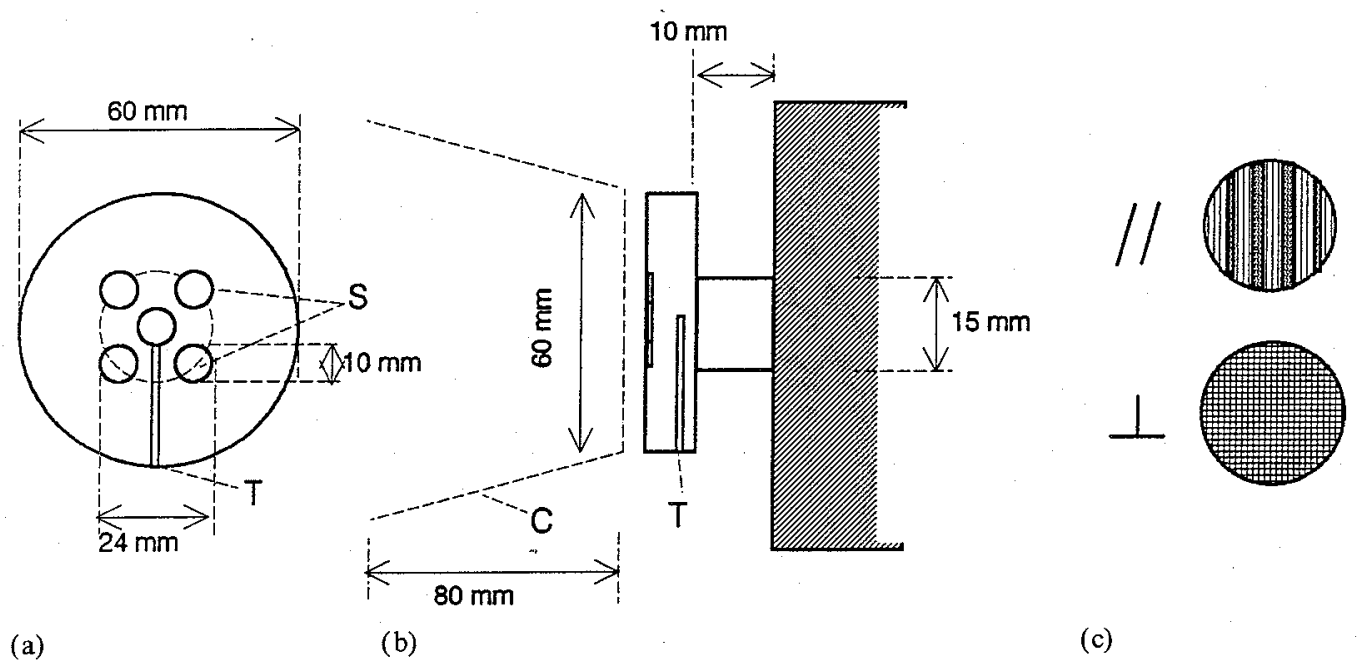

Fig. 4. (a) Front and (b) side view of the pedestal with the five substrate supports: $T$, thermocouple insert hole; $C$, optional recirculation cup. (c) Top view of CFC substrates in the two orientations (from ref. 5).

(2) The hydrocarbon injection rate $\left\{\mathrm{C}_{x} \mathrm{H}_{y}\right\}$, expressed in an inverse energy factor $Q\left(\mathrm{~W}^{-1}\right)$

$Q=\{\mathrm{C}\} /\left(\{\operatorname{Ar}\} P_{\text {arc }}\right)$

(3) The substrate temperature $T_{s}\left({ }^{\circ} \mathrm{C}\right)$.

For the actual purpose, the relation of layer quality with growth rate and layer thickness and the influence of the substrate type and feed gas (methane or acetylene) has also been studied.

In the present experimental configuration the desired deposition temperature is obtained by direct heating of the substrate by the plasma beam itself. It is a function of $d_{\mathrm{n}-\mathrm{s}}, P_{\mathrm{arc}}, p_{\mathrm{c}}$ and, to a minor extent, of the hydrogen and monomer admixture.

In order to achieve high substrate temperatures, on the movable sample support of Fig. 2 an extra pedestal with five substrate supports is mounted (Fig. 4(a), (b)). One of the substrate supports is centered because of the reduced deposition area (approximately $1 \mathrm{~cm}^{2}$ ) at high chamber pressures. An extensive range of substrate temperatures from 400 to $1400^{\circ} \mathrm{C}$ can be covered on different nozzle to substrate distances. Right underneath the center sample a chromel-alumel thermocouple for temperature checking is mounted. As actual deposition temperatures, the surface temperatures $T_{p y}$ as measured with an optical pyrometer (type Chino IR-AHIS) were adapted.

As substrates, $10 \mathrm{~mm}$ discs (thickness $5 \mathrm{~mm}$ ) of carbon fiber composite (CFC, Dunlop DMS 678) and stainless steel (type AISI $316 \mathrm{Ti}$ ) were used. The composite consists of plane matrices of carbon fibers, with pyrolytic graphite in between. CFC can be applied in two orientations: as a $\mathrm{CFC}_{\mid}$or as $\mathrm{CFC}_{\perp}$ substrate. The most useful orientation is $\mathrm{CFC}_{\|}$, with the fiber planes parallel to the surface normal. In this case the direction of highest thermal conductivity is perpendicular to the surface. In Fig. 4(c) a schematic view of the CFC surface is shown in the two orientations. As a pretreatment substrates can be polished, for equal reference conditions. The substrates were baked in vacuum at a temperature of $200^{\circ} \mathrm{C}$ for $24 \mathrm{~h}$, in order to dehydrate them. In most trials, a batch of several substrates was installed consisting of polished and unpolished $\mathrm{CFC}_{\|}$ and $\mathrm{CFC}_{\perp}$ substrates. Furthermore, a substrate of stainless steel (AISI $316 \mathrm{Ti}$ ) was mounted as an extra facility for weight gain determinations. In this way the influence of substrate material on morphology and Raman spectrum could be studied. Deposition times were on the order of $20 \mathrm{~min}$. Thicknesses and growth rates were estimated by weight change measurements, normalized to a density of $1 \mathrm{~g} \mathrm{~cm}^{-3}$. In general growth rates on the center substrate are higher than on the sideways placed substrates, particularly at high chamber pressures.

Some experiments with a modified substrate geometry were also performed. After finding the estimated optimal settings (trial $\mathrm{B} 40,47$ or 54) these trials were repeated with oblique incidence of the beam on the sample and with a recirculation cup (respectively B56 + 59 and B57). The aim of the former was to try to influence the orientation of the deposited graphite. In the latter trial the purpose was to create small convective cells over the substrate, in order to achieve an enhanced carbon deposition efficiency.

\section{Diagnostics}

\subsection{Raman spectroscopy set-up}

Spectra were recorded with the microRaman set-up (Dilor) of the Department of Inorganic Chemistry of the University of Amsterdam (Fig. 5).This arrangement 


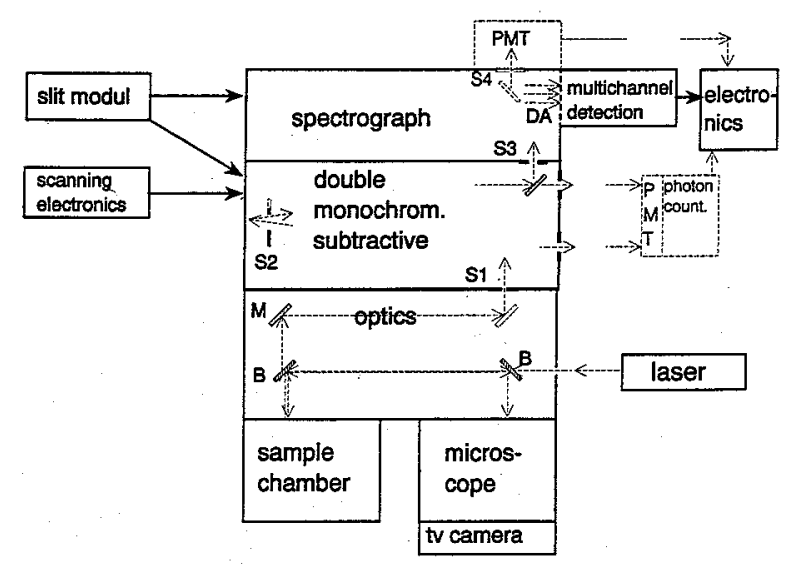

Fig. 5. Outline of the microRaman set-up with DA, the diode array for multichannel analysis: PMT, photo multiplier tubes for optional photon counting; $\mathrm{B}$, beam splitters; $\mathrm{M}$, mirrors; $\mathrm{SI}-4$, slits.

enables accurate laser spot adjustment and direct sample inspection. The spectra were measured in a $180^{\circ}$ backscattering geometry. As a source the $514.5 \mathrm{~nm}$ line of an argon ion laser was used. In general the power was $100 \mathrm{~mW}$ and the area of cross section $4 \mu^{2}$. Signal detection was done by means of a double monochromator (in the subtractive mode for straylight rejection) and a diode array with signal accumulation $(20 \times)$. The width of the apparatus profile was $6.6 \mathrm{~cm}^{-1}$. As this is still much smaller than the relevant peak widths, no deconvolution was performed.

\subsection{Set-up for thermal shock experiments}

In Fig. 6 an outline of the set-up for thermal shock testing is given. As a source a pulsed Nd-YAG laser (LASAG KLS-321) is used. The laser is equipped with a plan-parallel resonator with a length of $500 \mathrm{~mm}$ and a diaphragm with a diameter of $5.8 \mathrm{~mm}$. Experimental

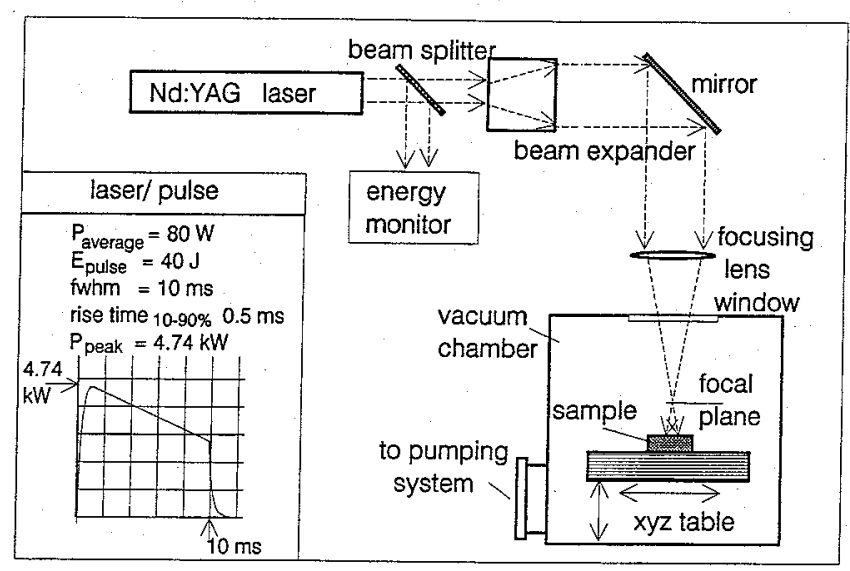

Fig. 6. Set-up for laser thermal shock tests (from ref. 15); in the inset some specific experimental data and the shape of the $10 \mathrm{~ms}$ pulse are given. conditions of the laser and the shape of the pulse are given in the inset of Fig. 6 .

The laser beam is transmitted to the specimen by an optical system. The beam is expanded to a diameter of $13 \mathrm{~mm}$ and then focused on the specimen by a lens (focal distance $100 \mathrm{~mm}$ ). The minimal spot diameter is $0.5 \mathrm{~mm}$ in the focal plane. The specimen is placed in a vacuum chamber with a pressure of less than $10^{-2} \mathrm{~Pa}$. By positioning the specimen out of focus, the spot diameter and the energy density on its surface can be varied. Assuming a homogeneous distribution of the intensity over the laser beam, the spot diameter $c$ (in $\mathrm{mm}$ ) at the defocus distance $x$ (in $\mathrm{mm}$ ) can simply be calculated according to the following formula:

$c=(x+4) /(100+4) \times 13$

For example with a defocus distance of $30 \mathrm{~mm}$, the energy density is $2.82 \mathrm{MJ} \mathrm{m}^{-2}$. For the actual values of $x$ the relative inaccuracy in the energy density is about two times the relative inaccuracy in $x$, which means only about $2 \%$.

For an inhomogeneous distribution of the intensity over the laser beam all of the energy density values used in this investigation should be corrected to a peak energy density of 1.3 times the given values [13,14]. More details on the facility can be found elsewhere [15].

The results of the thermal shock testing, were primarily quantified by the parameter erosion threshold, i.e. the lower limit of the laser pulse power at which erosion starts to occur. Secondly, a qualitative study of the damage by a $3 \mathrm{MJ} \mathrm{m}^{-2}$ energy dump (in $10 \mathrm{~ms}$ ) was performed.

\section{Results and discussion}

\subsection{Introduction}

In this section, the morphology and Raman spectra of the films, their macroscopic properties, the relations between Raman spectrum parameters and the erosion resistance of the coatings on the one hand and the reactor parameters during deposition on the other hand, growth rates and efficiency, the qualitative damage study, and some particular deposition results are presented.

\subsection{Morphology and crystallinity of the coatings;} hydrogen admixture, the principal determining factor

In Fig. 7(a) an example of the typical morphology of a graphitic film grown without or with a small amount of hydrogen admixture is shown. A cauliflower or ball-like morphology with a columnar growth mechanism can be observed. Its appearance is similar to that of conventional pyrolytic carbon [16]. In pyrolytic carbon the basal planes are quasi-parallel to the substrate surface. It is not sure whether this was the case for our 


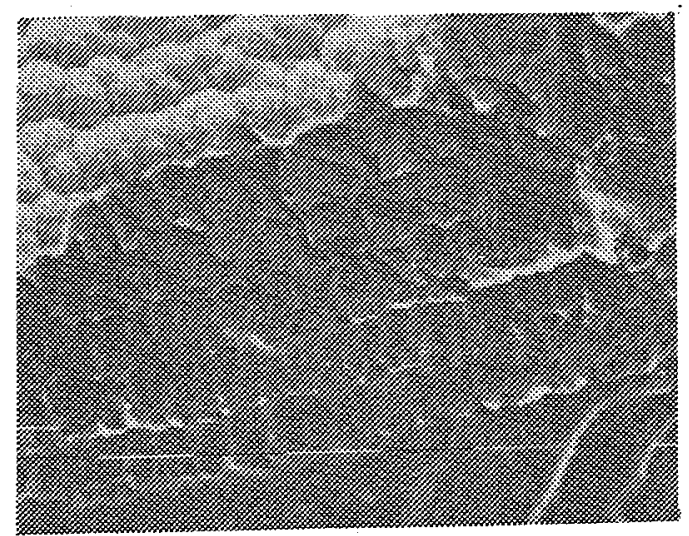

(a)

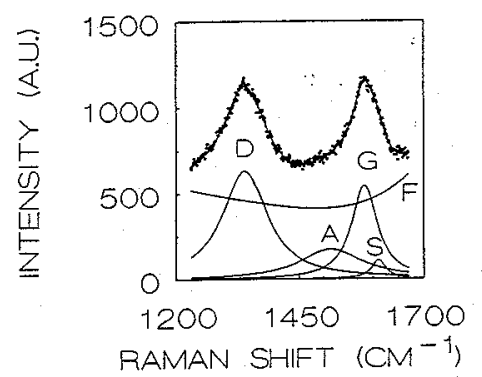

(b)

Fig. 7. (a) SEM image (side view, 1 bar $=100 \mu \mathrm{m}$ ) and (b) Raman spectrum of a typically amorphous graphite film (B19): substrate steel; $d_{\mathrm{n}-\mathrm{s}}=10 \mathrm{~cm} ;\left\{\mathrm{C}_{2} \mathrm{H}_{2}\right\}=8,\left\{\mathrm{H}_{2}\right\}=8, H_{\text {tot }} / C=2 ; T_{\mathrm{py}}=$ $860^{\circ} \mathrm{C} ; p_{\mathrm{c}}=10^{2} \mathrm{~Pa} ; P_{\mathrm{arc}}=3.12 \mathrm{~kW} ; Q=51 \times 10^{-6} \mathrm{~W}^{-1} ; d=359 \mu \mathrm{m} ;$ $R_{\mathrm{d}}=99 \mathrm{~nm} \mathrm{~s}^{-1}$.

deposits too. Possibly there is no two-dimensional ordering of the basal planes at all, and we are dealing with isotropically distributed nanocrystallites of graphite. In Fig. 7(b) the Raman spectrum of the film is shown. It is typical for nanocrystalline graphite without long range order $[17,18]$. All of the films deposited in the previous research stage [4] had a similar spectrum. The following features are present, denoted by their specific character: the single-crystal graphite peak $G$ ( $\mathrm{sp}^{2}$ bonding), shifted with respect to its ideal position at $1581 \mathrm{~cm}^{-1}$; a defective graphite peak D at about $1355 \mathrm{~cm}^{-1}$ and a shoulder $\mathrm{S}$ at about $1621 \mathrm{~cm}^{-1}$, originating by edge effects of the finite microcrystals; a component $\mathrm{A}$ at approximately $1500 \mathrm{~cm}^{-1}$, which is often observed in a-C:H [17]; a fluorescence background F. In the following we refer to this material as "amorphous graphite", and denote it as AG.

The spectra were resolved into their components by a least squares fitting program [19]. It appears that they are best fitted by lorentzian distributions, in accordance with ref. 20, on top of the background. In the case of highly crystalline graphite, e.g. HOPG, only a sharp G-peak would be present [21]. Several methods for deducing information on the quality of the material are given in the literature. A measure for the crystallite size of the graphite can be deduced from the intensity ratio of the $\mathrm{D}$ and the G peak $I_{\mathrm{d}} / I_{\mathrm{g}}$ [21] and from the shift of the $G$ peak with respect to its ideal value [18]. From the widths of the $D$ and $G$ peaks an impression of the degree of amorphization can be obtained [22]. A study of the shoulder $\mathrm{S}$ gives an indication of quality [23]. We will mainly use the $I_{\mathrm{d}} / I_{\mathrm{g}}$ intensity ratio as a quality indication; in Section 5.4 the use of the other Raman parameters is briefly discussed.

The crystallinity of our deposited materials was improved by increasing the hydrogen addition. In the sequence of Fig. 8(a) -(c) the gradual structural transition with increasing hydrogen admixture is illustrated. All other reactor parameters were kept approximately the same. The defective graphite $1355 \mathrm{~cm}^{-1} \mathrm{D}$ peak decreases strongly with respect to the $1581 \mathrm{~cm}^{-1} \mathrm{G}$ peak. In comparison with Fig. 7(b) the amorphous component could not be resolved significantly. In Fig. 8(d) the morphology of the film of Fig. 8(c) is shown. Distinct foliates can be observed, with dimensions of several micrometers, obviously separated by pores. Most likely, the foliates are actually oriented graphite single crystals. Estimating the crystallite size from the ratio $I_{\mathrm{d}} / I_{\mathrm{g}}$ according to Tuinstra and König [21] in the sequence Fig. 8(a)-(c), we obtain an increase from approximately 3 to $30 \mathrm{~nm}$. The discrepancy with the dimensions observed in the SEM image of Fig. 8(d) may be caused by the presence of minor misorientations of the basal planes within the crystals [24].

\subsection{Macroscopic properties of the films: appearance,} cohesion and adhesion, density

Macroscopically all of the materials which were produced with $\mathrm{CH}_{4}$, or with low amounts of $\mathrm{C}_{2} \mathrm{H}_{2}$ admixtures (less than 1 standard $\mathrm{cm}^{3} \mathrm{~s}^{-1}$ ), consist of a black, sooty material with poor coherence. As a consequence the adhesion of these layers as a whole to the substrates was weak. It was found that the principal requirement for obtaining coherent and hard films is the use of $\mathrm{C}_{2} \mathrm{H}_{2}$ at high flow rates ( 8 standard $\mathrm{cm}^{3} \mathrm{~s}^{-1}$ ). An additional advantage of the high flow rate are high growth rates, tens to hundreds of nanometers per second on several square centimetres, for crystalline graphite (CG) and $A G$ coatings respectively. In the thick (approximately $1 \mathrm{~mm}$ ) AG films the cauliflower structure could even be observed visibly. The CG films are smoother. Most likely the materials are a kind of hard carbon without hydrogen (i-C), with predominantly (in $\mathrm{AG}$ ) or exclusively (in $\mathrm{CG}$ ) $\mathrm{sp}^{2}$ bondings. Similarity with the sooty and hard materials (re)deposited onto the walls of a tokamak during operation can be noted [10].

In general, the adhesion of the layers depends on the type of substrate; for all graphitic films adhesion to 


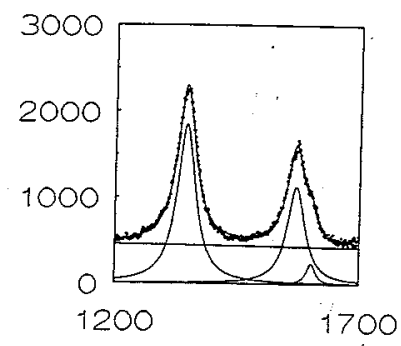

(a)

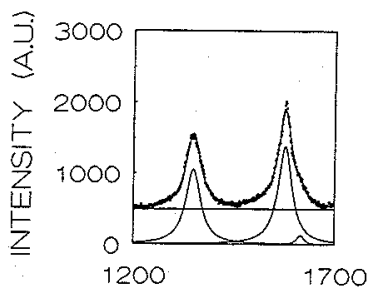

(b)

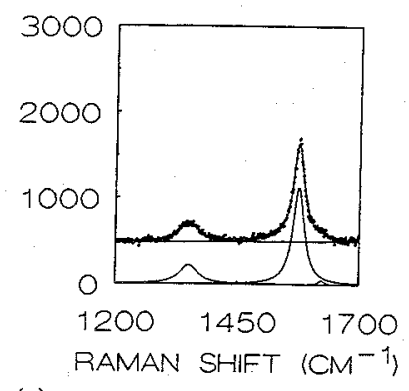

(c)

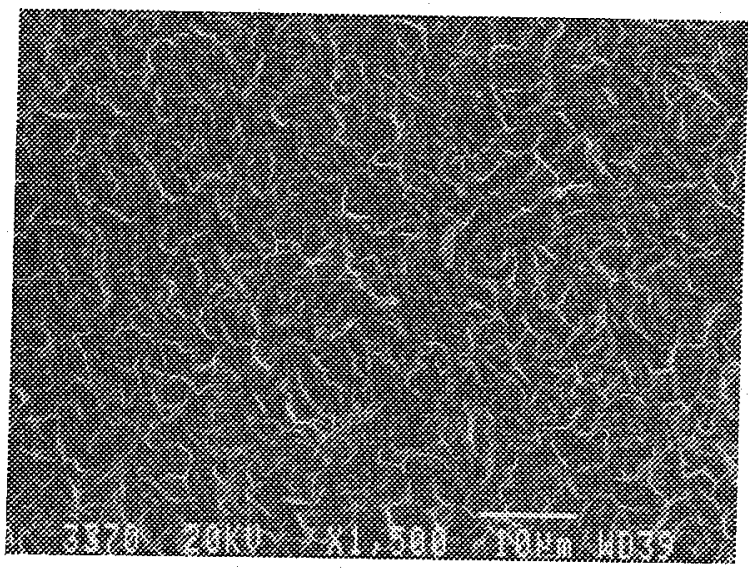

(d)

Fig. 8. (a)-(c) Effect of increasing $\mathrm{H}_{2}$ admixture on the Raman spectrum, with other reactor settings constant: $\left\{\mathrm{C}_{2} \mathrm{H}_{2}\right\}=1$; $P_{\text {arc }} \approx 2.6 \mathrm{~kW} ; Q \approx 7 \times 10^{-6} \mathrm{~W}^{-1} ; p_{\mathrm{c}}=10^{2} \mathrm{~Pa} ; T_{\mathrm{py}} \approx 840^{\circ} \mathrm{C}$; increasing $\mathrm{H}_{2}$ addition, 5,10 and 20 standard $\mathrm{cm}^{3} \mathrm{~s}^{-1}$ respectively. (d) Micrograph of the film of (c).

steel substrates is poor; the adhesion to CFC substrates is rather good for the AG films, and excellent for the CG films (film coalesced to substrate).

A well known feature of amorphous films grown by various methods is the existence of large voids between columnar growth structures, leading to a very porous

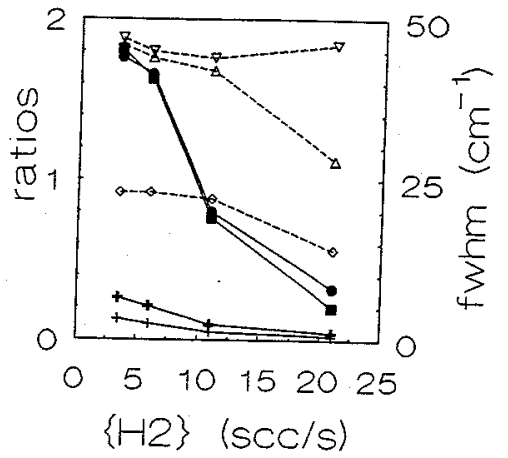

Fig. 9. Covariation of various Raman fit parameters: $I_{\mathrm{d}} / I_{\mathrm{g}}$, $A_{\mathrm{d}} / A_{\mathrm{g}},+I_{\mathrm{s}} / I_{\mathrm{g}},+A_{\mathrm{s}} / A_{\mathrm{g}}$ (left axis), $\nabla d_{\mathrm{d}}, \Delta d_{\mathrm{g}}, \diamond d_{\mathrm{s}}$ (right axis).

material [16, 25]. Comparing thickness estimates from SEM images and from weight change measurements, it appears that both our AG and CG coatings have a low density: approximately $0.5-1 \mathrm{~g} \mathrm{~cm}^{-3}$, compared with a value of $2.27 \mathrm{~g} \mathrm{~cm}^{-3}$ for HOPG [24]. It is expected that by optimizing the substrate geometry and chamber pressure higher densities can be achieved in the future.

\subsection{Relations of the Raman spectra parameters and the} thermal shock resistance with the deposition conditions

Similar to Tuinstra and König [21], we studied the intensity (peak height) ratio of the D and G peaks $I_{\mathrm{d}} / I_{\mathrm{g}}$ as a suitable parameter for describing the crystallinity of the materials. For our materials we found a direct linear relation with the integrated intensity (peak area) ratio $A_{\mathrm{d}} / A_{\mathrm{g}}$. Furthermore, globally, linear relations of this ratio with the full widths at half maximum (FWHM) of D, G and S peaks $\left(d_{\mathrm{d}}, d_{\mathrm{g}}, d_{\mathrm{s}}\right)$, and with the intensity ratios of the $\mathrm{A}$, and the $\mathrm{S}$ peak with the $\mathrm{G}$ peak $\left(A_{\mathrm{a}} / A_{\mathrm{g}}\right.$ and $\left.A_{\mathrm{s}} / A_{\mathrm{g}}\right)$ exist, so these do not render much extra information. As an example this is illustrated in Fig. 9 for the trial sequence of Fig. 8. For this specific trial sequence the width $d_{\mathrm{d}}$ of the $\mathrm{D}$ peak does not decrease. In general, however, we obtained an approximately constant ratio for the width of the $D$ and the $G$ peaks. As a second example in Fig. 10 an almost linear relation exists between the intensity ratio $I_{\mathrm{s}} / I_{\mathrm{g}}$ of the shoulder $\mathrm{S}$ and the $\mathrm{G}$ peaks, and the intensity ratio $I_{\mathrm{d}} / I_{\mathrm{g}}$, in agreement with ref. 23 .

In the following the results of Raman spectroscopy and of the laser heat shock tests are treated quantitatively as a function of the most relevant parameters hydrogen admixture, growth rate, inverse energy factor $Q$ and deposition temperature measured by pyrometry $T_{\mathrm{py}}$. The Raman measurements served as a direct feedback diagnostic medium on a selected number of samples for finding trends during the project. It appeared that the Raman intensity ratio $\left(I_{\mathrm{d}} / I_{\mathrm{g}}\right)$ was only a function of the hydrogen addition, and the growth rate. These relations are shown in Fig. 11(a) and 12(a). No 


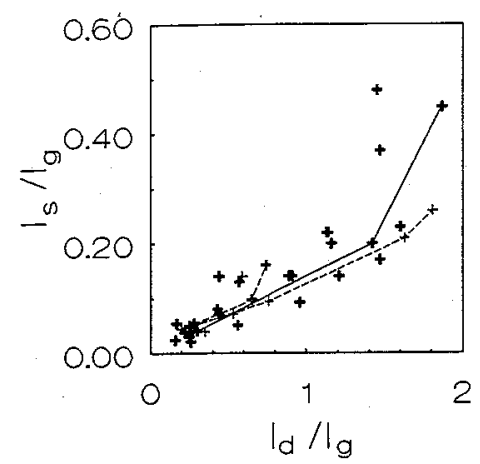

Fig. 10. Relation between Raman fit parameters $I_{\mathrm{d}} / I_{\mathrm{g}}$ and $I_{\mathrm{s}} / I_{\mathrm{g}}$.

\begin{tabular}{llll}
\hline Lines of constant $Q$ factor & \\
\hline,++ & CFC & Steel & various \\
-+- & CFC & $Q \approx$ & $3 \times 10^{-6} \mathrm{~W}^{-1}$ \\
-+- & CFC & $Q \approx$ & $60 \times 10^{-6} \mathrm{~W}^{-1}$ \\
-+- & St & $Q \approx$ & $7 \times 10^{-6} \mathrm{~W}^{-1}$ \\
\hline
\end{tabular}

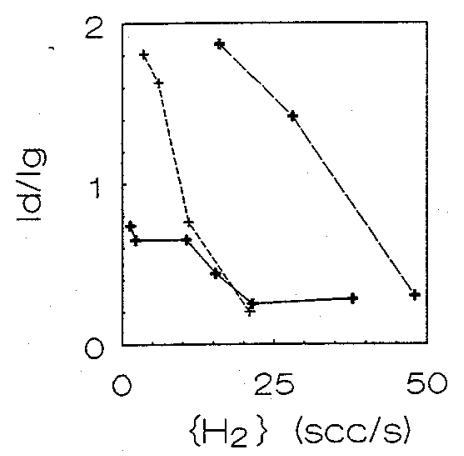

(a)

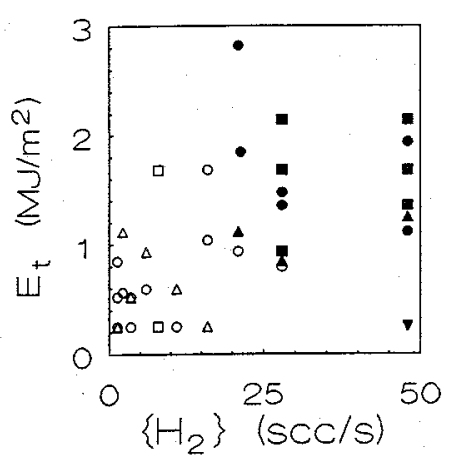

(b)

Fig. 11. (a) Raman intensity ratio (see Fig. 10 for legend) and (b) erosion threshold vs. total $\mathrm{H}_{2}$ input $\left\{\mathrm{H}_{2}\right\}$.

\begin{tabular}{lll}
\hline CG & AG & Substrate \\
\hline$\bullet$ & 0 & CFC \\
$\Delta$ & $\triangle$ & Steel \\
$\square$ & $\square$ & CFC special trial \\
$\nabla$ & $\nabla$ & Steel special trial \\
\hline
\end{tabular}

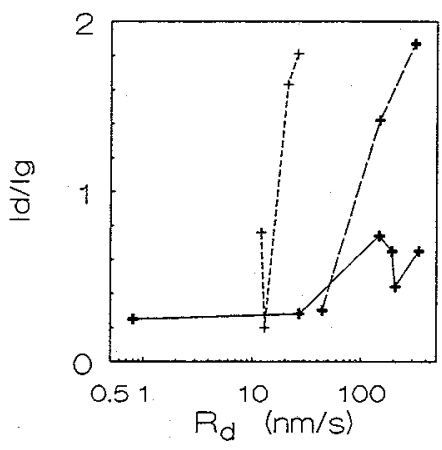

(a)

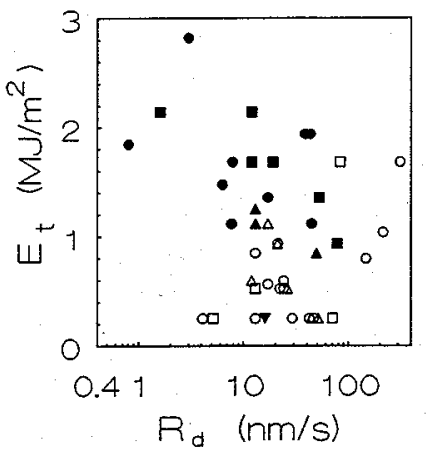

(b)

Fig. 12 (a) Raman intensity ratio (see Fig. 10 for legend) and (b) erosion threshold $v s$. growth rate $R_{\mathrm{d}}$ (see Fig. 11 for legend).

definite functional relationship between the Raman intensity ratio and $Q$ or $T_{\mathrm{py}}$ could be found, so these graphs are not shown.

The erosion threshold values $E_{\mathrm{t}}$ were determined afterwards. In the graphs of the erosion thresholds all available data are displayed in order to find global trends. All the results are for layers deposited onto polished $\mathrm{CFC}_{\|}$or steel substrates. Furthermore, all erosion threshold measurements were accompanied by SEM observations. The results of these observations are included in the figures: whenever the coating exhibited the foliate structure of $\mathrm{CG}$, a solid symbol is used. When the coating had the cauliflower-like structure of $\mathrm{AG}$ an open symbol is used. Furthermore, the results of the modified-geometry trials are denoted by a specific symbol.

In Fig. 11(a) and (b) the role of $\mathrm{H}_{2}$ admixture is clearly illustrated. In Fig. 11(b) it can be observed that both the erosion threshold and the crystallinity increase with increasing hydrogen admixture, consistent with the decrease in Raman intensity ratio in Fig. 11(a). In Fig. 12(b) it can be observed that the layers with the top values of erosion threshold have been obtained for the lowest growth rates. These low growth rates are a direct consequence of high hydrogen admixtures. The large scatter in Fig. 12(b), however, shows that for the 
TABLE 1. Trials with lowest Raman intensity ratios $I_{\mathrm{d}} / I_{\mathrm{g}}$ and highest erosion thresholds $E_{\mathrm{t}}$, in relation to reactor parameters $\left\{\mathrm{C}_{2} \mathrm{H}_{2}\right\}$ and $\left\{\mathrm{H}_{2}\right\}$, film thickness $d$, growth rate $R_{\mathrm{d}}$, and approximated deposited area $A_{\mathrm{d}}: d_{\mathrm{n}-\mathrm{s}}=5 \mathrm{~cm}$ and $p_{\mathrm{c}}=10^{2} \mathrm{~Pa}$ unless indicated otherwise

\begin{tabular}{|c|c|c|c|c|c|c|c|c|}
\hline Sample & $\begin{array}{l}\left\{\mathrm{C}_{2} \mathrm{H}_{2}\right\} \\
\text { (standard } \\
\mathrm{cm}^{3} \mathrm{~s}^{-1} \text { ) }\end{array}$ & $\begin{array}{l}\left\{\mathrm{H}_{2}\right\} \\
\text { (standard } \\
\left.\mathrm{cm}^{3} \mathrm{~s}^{-1}\right)\end{array}$ & $\begin{array}{l}d \\
(\mu \mathrm{m})\end{array}$ & $\begin{array}{l}R_{\mathrm{d}} \\
\left(\mathrm{nm} \mathrm{s}^{-1}\right)\end{array}$ & $\begin{array}{l}A_{\mathrm{d}} \\
\left(\mathrm{cm}^{2}\right)\end{array}$ & $I_{\mathrm{d}} / I_{\mathrm{g}}$ & $\begin{array}{l}E_{\mathrm{t}} \\
\left(\mathrm{MJ} \mathrm{m}^{-2}\right)\end{array}$ & Remarks \\
\hline B38c & 1 & 21 & 4 & 3 & 7.5 & - & 2.82 & \\
\hline $\begin{array}{l}\text { B57c } \\
\text { B57St }\end{array}$ & 8 & 40 & $\begin{array}{l}57 \\
76\end{array}$ & $\begin{array}{l}12 \\
16\end{array}$ & $\begin{array}{l}7.5 \\
12\end{array}$ & $\overline{0.14}$ & $\begin{aligned} & 2.14 \\
< & 0.5\end{aligned}$ & $\begin{array}{l}\text { Recirculation cup, } \\
d_{\mathrm{n}-\mathrm{s}}=8 \mathrm{~cm}\end{array}$ \\
\hline $\begin{array}{l}\text { B47 } \\
\text { B } 47 \mathrm{c}\end{array}$ & 8 & 40 & $\begin{array}{r}39 \\
212\end{array}$ & $\begin{array}{l}7.9 \\
44\end{array}$ & $\begin{array}{l}7.5 \\
7.5\end{array}$ & $\begin{array}{l}0.16 \\
0.30\end{array}$ & $\begin{array}{l}1.68 \\
1.12\end{array}$ & Optimum \\
\hline $\begin{array}{l}\text { B54 } \\
\text { B54c } \\
\text { B55 }\end{array}$ & 8 & 40 & $\begin{array}{r}204 \\
\approx 1900 \\
193\end{array}$ & $\begin{array}{r}43 \\
\approx 400 \\
38\end{array}$ & $\begin{array}{l}0.75 \\
0.75 \\
0.75\end{array}$ & $\begin{array}{l}0.22 \\
1.66 \\
0.25\end{array}$ & $\frac{1.94}{1.94}$ & $\begin{array}{l}\text { Optimum, but } \\
p_{c} \uparrow 10^{3} \mathrm{~Pa} \\
\text { repetition of } \mathrm{B} 54\end{array}$ \\
\hline $\mathrm{B} 52 \mathrm{c}$ & $3 / 8$ & 21 & 2 & 0.8 & 0.75 & 0.25 & 1.85 & $p_{\mathrm{c}}=10^{3} \mathrm{~Pa}$ \\
\hline $\begin{array}{l}\mathrm{B} 40 \mathrm{c} \\
\mathrm{B} 56 \mathrm{c} \\
\mathrm{B} 59 \mathrm{c}\end{array}$ & 8 & 20 & $\begin{array}{r}265 \\
69 \\
282\end{array}$ & $\begin{array}{r}147 \\
19 \\
78\end{array}$ & $\begin{array}{l}7.5 \\
7.5 \\
0.75\end{array}$ & $\begin{array}{l}1.42 \\
0.26 \\
0.25\end{array}$ & $\begin{array}{l}0.80 \\
1.68 \\
0.94\end{array}$ & $\begin{array}{l}\text { oblique incidence } \\
\text { oblique incidence, } p_{\mathrm{c}} \uparrow 10^{3} \mathrm{~Pa}\end{array}$ \\
\hline B46c & 8 & 40 & $\approx 2300$ & $\approx 2600$ & 0.13 & 0.43 & - & $p_{\mathrm{c}}=6 \times 10^{3} \mathrm{~Pa}$ \\
\hline $\mathrm{B} 8 \mathrm{c}$ & 8 & 20 & 5.9 & 1.6 & 30 & 0.44 & 2.14 & $d_{\mathrm{n}-\mathrm{s}}=20 \mathrm{~cm}$ \\
\hline $\begin{array}{l}\text { B39c } \\
\text { B34 }\end{array}$ & $\begin{array}{l}8 \\
8\end{array}$ & $\begin{array}{l}8 \\
0\end{array}$ & $\begin{array}{r}377 \\
42\end{array}$ & $\begin{array}{r}314 \\
83\end{array}$ & $\begin{array}{l}7.5 \\
15\end{array}$ & $\begin{array}{l}1.87 \\
-\end{array}$ & $\begin{array}{l}1.68 \\
1.68\end{array}$ & $\begin{array}{l}\mathrm{AG} \\
\mathrm{AG}, d_{\mathrm{n}-\mathrm{s}}=10 \mathrm{~cm} \\
\quad \text { bias }-261 \mathrm{~V}\end{array}$ \\
\hline
\end{tabular}

c, sample in center position of pedestal; St, steel.

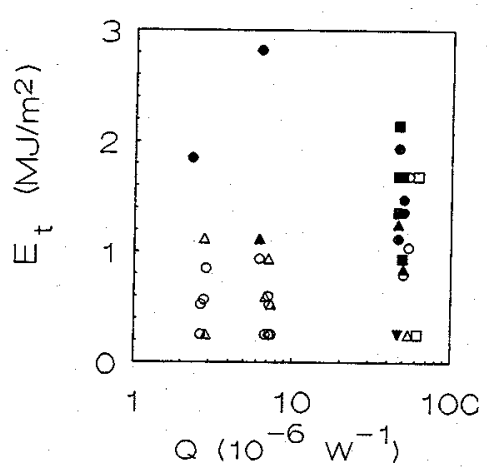

Fig. 13. Erosion threshold $v s$. inverse energy factor $Q$ (see Fig. 11 for legend).

medium $E_{\mathrm{t}}$ values the relation of coating quality with growth rate is certainly not strict. A few of the fast grown amorphous coatings (B34 and B39) have a relatively high $E_{\mathrm{t}}$ or 1.68 . Crystalline graphite (low Raman intensity ratios) with high $E_{\mathrm{t}}$ of up to $1.94 \mathrm{MJ} \mathrm{m}^{-2}$ were also produced at reasonably high rates (tens of nanometers per second), e.g. in trials B47 and B54 and B55 (see Table 1).

In Figs. 13 and 14 erosion thresholds are given in relation to $Q$ and $T_{\text {py }}$ respectively. In Fig. 13 it can be observed that particularly for high values of $Q$ (around $60 \times 10^{-6} \mathrm{~W}^{-1}$ ) the higher values of erosion threshold were measured. These $Q$ values are epuivalent with an

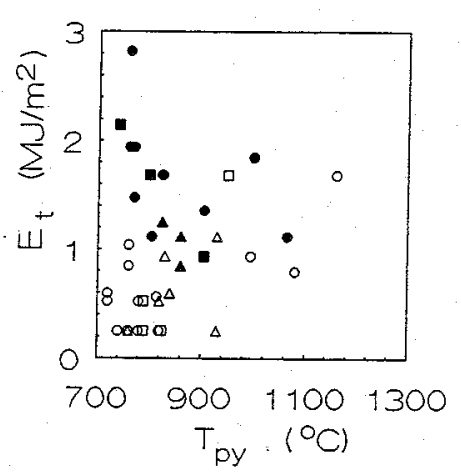

Fig. 14. Erosion threshold vs. deposition temperature by pyrometry $T_{\mathrm{py}}$ (see Fig. 11 for legend).

acetylene flow rate of 8 standard $\mathrm{cm}^{3} \mathrm{~s}^{-1}$. This result confirms the observation (not shown here) that $E_{\mathrm{t}}$ does not explicitly depend on the $[\mathrm{H}] /[\mathrm{C}]$ ratio but rather on the absolute hydrogen admixture (Fig. 11(b)). High absolute hydrogen admixtures together with high $Q$ values give a low $[\mathrm{H}] /[\mathrm{C}]$ value, but a high $E_{\mathrm{t}}$. In Fig. 14 two tendencies seem to be present. For the CG materials (full symbols) the erosion thresholds $E_{\mathrm{t}}$ tends to decrease, and for the AG coatings (open symbols) $E_{\mathrm{t}}$ tends to increase with increasing deposition temperatures. The first effect is caused by the fact that the large hydrogen admixtures used for the deposition of 
crystalline coatings quench the plasma, and so reduce the plasma heating of the substrate. For the second effect no explanation is available yet.

Concerning the erosion threshold as a function of coating thickness, a distribution similar to that of Fig. 12 (b) is obtained, because of the direct coupling of thickness with growth rate. This implies that as a function of thickness only, taking into account the influence of the growth rate, no real deterioration of the erosion resistance is present.

Regarding the influence of substrate type, it has been observed that, comparing the erosion thresholds for coatings on steel and on CFC that have been deposited under the same conditions, in general the erosion thresholds on steel are lower.

\subsection{Summary and evaluation of results of the diagnostics}

The best results of Raman intensity ratio and erosion threshold are summarized in Table 1. In interesting cases the results for more samples of the same batch are also given. The reduction in deposition area at high chamber pressures $p_{\mathrm{c}}$ is taken into account by dividing the estimated area of deposition for $1 \mathrm{mbar}$ by $p_{\mathrm{c}}$ (in millibars).

The best coating 38 shows slight erosion at an energy density of $2.82 \mathrm{MJ} \mathrm{m}^{-2}$. (For comparison, the CFC substrate begins to show erosion at about $2.8 \mathrm{MJ} \mathrm{m}^{-2}$ [5]). According to SEM observations this is a crystalline coating. However, the coating thickness is only $4 \mu \mathrm{m}$. The second best coatings are B8 and B57 with a threshold of $2.14 \mathrm{MJ} \mathrm{m}^{-2}$. These are all crystalline coatings on a substrate of $\mathrm{CFC}_{\|}$. Coating numbers B57 were made by means of a cup to control the mass flow towards the substrate better. The result for coating B39c is striking. It is an amorphous graphite coating, with a very high deposition rate and a relatively high erosion threshold. The coatings B40 and B56 were deposited under somewhat less favorable, equal settings. In trial 56 the substrate had been tilted with respect to the plasma beam. It can be noticed that this may improve the thermal shock resistance. The best coating on steel is sample B47St with a threshold of $1.25 \mathrm{MJ} \mathrm{m}^{-2}$. The coating is also crystalline. The conditions of trial $\mathrm{B} 47\left(T_{\mathrm{py}}=825^{\circ} \mathrm{C}, p_{\mathrm{c}}=10^{2} \mathrm{~Pa}\right)$ are considered as representing the optimal reactor settings for crystalline graphite deposition so far, and equally 54 and 55 with a higher $p_{\mathrm{c}}$. All three trials yield coatings with a high erosion threshold.

Considering the equal results of trials 54 and 55 it can be deduced that the reproducibility of both the deposition process and the erosion threshold measurement is good.

In Fig. 15 the results of Raman spectroscopy and erosion threshold are combined. In general the highest $E_{\mathrm{t}}$ values coincide with the most crystalline coatings according to the Raman spectrum. This means that

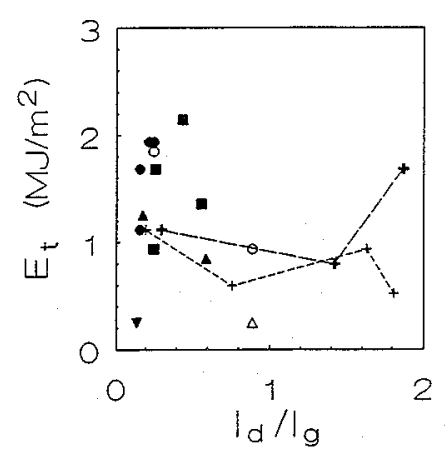

Fig. 15. Erosion threshold vs. Raman intensity ratio (see Figs. 10 and 11 for legend).

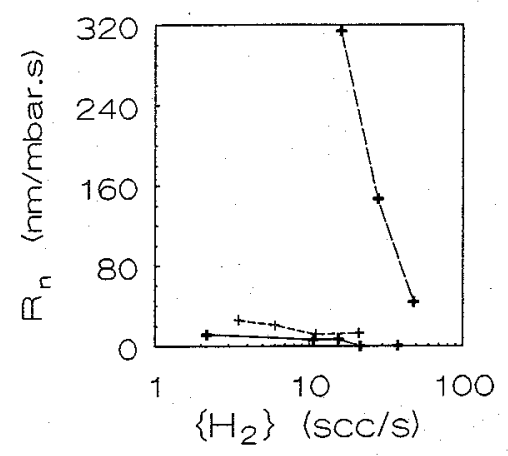

Fig. 16. Normalized growth rate vs. total hydrogen input (see Fig. 10 for legend).

Raman spectroscopy is a suitable means for a first fast prediction of the thermomechanical properties of the coating. There are exceptions, e.g. B39, an amorphous coating with a high erosion threshold. Other properties (e.g. density) of the coating play an important part in determining the thermomechanical qualities.

\subsection{Growth rate and efficiency considerations}

In Fig. 16 the normalized growth rates as a measure for the volume deposition rate are shown as a function of the hydrogen admixtures. The deposition rates decrease with increasing hydrogen admixtures generally. In order to control the relative etching effect by the hydrogen radicals, the use of a small nozzle to substrate distance of $5 \mathrm{~cm}$ was necessary. The area of deposition was measured directly on the sample pedestal. It appears that this area is somewhat larger than the crosssection area of the actual (light emitting) plasma beam as shown in Fig. 3. This is because stagnation by the pedestal causes a sideways expanding flow of plasma over the pedestal. For $d_{\mathrm{n}-\mathrm{s}}=5 \mathrm{~cm}$ and $p_{\mathrm{c}}=10^{2} \mathrm{~Pa}$ the area of deposition $A_{\mathrm{d}}$ is approximately $7.5 \mathrm{~cm}$. This value is used as the standard value, and can be linearly adjusted for $d_{\mathrm{n}-\mathrm{s}}$ and reciprocically for $p_{\mathrm{c}}$. Again the three lines for constant $Q$ are drawn. The two dashed 
TABLE 2. Summary of deposited areas, equivalent deposition rates, observed deposition rates and deduced deposition efficiency factor $F$

\begin{tabular}{|c|c|c|c|c|c|c|}
\hline $\begin{array}{l}A_{\mathrm{d}} \\
\left(\mathrm{cm}^{2}\right)\end{array}$ & $\begin{array}{l}R_{\mathrm{eq}} \\
\left(\mathrm{nm} \mathrm{s}^{-1}\right)\end{array}$ & $\begin{array}{l}\mathrm{R}_{\mathrm{d}} \\
\left(\mathrm{nm} \mathrm{s}^{-1}\right)\end{array}$ & $F$ & Type & $\begin{array}{l}\text { reference } \\
\text { or } \\
\text { sample }\end{array}$ & Remarks \\
\hline 3 & 93 & 10 & 0.11 & Diamond & {$[3]$} & $\left\{\mathrm{CH}_{4}\right\}=0.2$ \\
\hline 7.5 & 10410 & 44 & 0.004 & $\mathrm{CG}$ & B47 & $\left\{\mathrm{C}_{2} \mathrm{H}_{2}\right\}=8$ \\
\hline 7.5 & 1301 & 21 & 0.016 & CG & B38 & $\left\{\mathrm{C}_{2} \mathrm{H}_{2}\right\}=1$ \\
\hline 7.5 & 10410 & 314 & 0.03 & $\mathrm{AG}$ & B39 & $\left\{\mathrm{C}_{2} \mathrm{H}_{2}\right\}=8$ \\
\hline 7.5 & 1301 & 196 & 0.15 & $\mathrm{AG}$ & B35 & $\left\{\mathrm{C}_{2} \mathrm{H}_{2}\right\}=1$ \\
\hline 30 & 2603 & 383 & 0.15 & $\mathrm{AG}$ & B5 & $\left\{\mathrm{C}_{2} \mathrm{H}_{2}\right\}=8$ \\
\hline 120 & 239 & 200 & 0.84 & $\mathrm{a}-\mathrm{C}: \mathrm{H}$ & {$[2]$} & $\left\{\mathrm{C}_{2} \mathrm{H}_{2}\right\}=6.7$ \\
\hline
\end{tabular}

lines are for trials with a chamber pressure of 1 mbar. The solid line represents a trial sequence with various high chamber pressures. In this view mostly the results for the high $Q$ values $\left(\mathrm{Q} \approx 60 \times 10^{-6} \mathrm{~W}^{-1}\right)$, i.e. a high acetylene flow of 8 standard $\mathrm{cm}^{3} \mathrm{~s}^{-1}$, are practically useful. For smaller deposition areas, with these high $Q$ values, CG can be obtained with much higher (linear) growth rates, e.g. B46 (more than $2000 \mathrm{~nm} \mathrm{~s}^{-1}$ !).

A way of describing the efficiency of the deposition process is the following. A monomer flow rate of 1 standard $\mathrm{cm}^{3} \mathrm{~s}^{-1}$ (at room temperature) means a carbon injection rate rate of $0.488 \mathrm{mg} \mathrm{s}^{-1}$ for each carbon atom. When every carbon particle is deposited at the substrate we have the following equivalent deposition rate (in nanometers per second)

$R_{\text {eq }}=4.88 \times 10^{3} \Phi n / \rho A_{\mathrm{d}}$

with $n$ the number of carbon atoms in the monomer, $\Phi$ (standard $\left.\mathrm{cm}^{3} \mathrm{~s}^{-1}\right)$ the monomer flow rate $\rho\left(\mathrm{g} \mathrm{cm}^{-3}\right)$ the density of the deposit, $A_{\mathrm{d}}\left(\mathrm{cm}^{2}\right)$ the estimated area of deposition. We define an efficiency factor $F$ as the ratio of the observed and of the equivalent deposition rate, $F=R_{\mathrm{d}} / R_{\text {eq }}$. In Table 2 the most interesting results are given (for AG and CG calculated with $\rho=1 \mathrm{~g} \mathrm{~cm}^{-3}$ ). In the calculations the inhomogeneity of the growth rate over the area was not taken into account.

It can easily be calculated that, with a flow rate of 1 standard $\mathrm{cm}^{3} \mathrm{~s}^{-1}$ and a deposition efficiency $F$ of unity, it would take approximately 1200 days to repair a typical disruption erosion damage. For $\mathrm{AG}$ with an $F$ of 0.1 and with the application of ten arcs with a flow rate $\left\{\mathrm{C}_{2} \mathrm{H}_{2}\right\}=10$ standard $\mathrm{cm}^{3} \mathrm{~s}^{-1}$ (essential to keep the number of arcs limited!) a value of about 120 days is obtained. With the application of more arcs this period could be reduced further, or CG ( $F$ typically about 0.01 ) could be applied. Covering the total divertor plate area of $200 \mathrm{~m}^{2}$ would take 50 times as long, so this is problematic.

The calculations for diamond and a:C-H $([2,3])$, although unsuited for the present purpose, are interesting. For diamond we obtain a surprisingly high $F$ of approximately 0.11 . However, because of the low flow

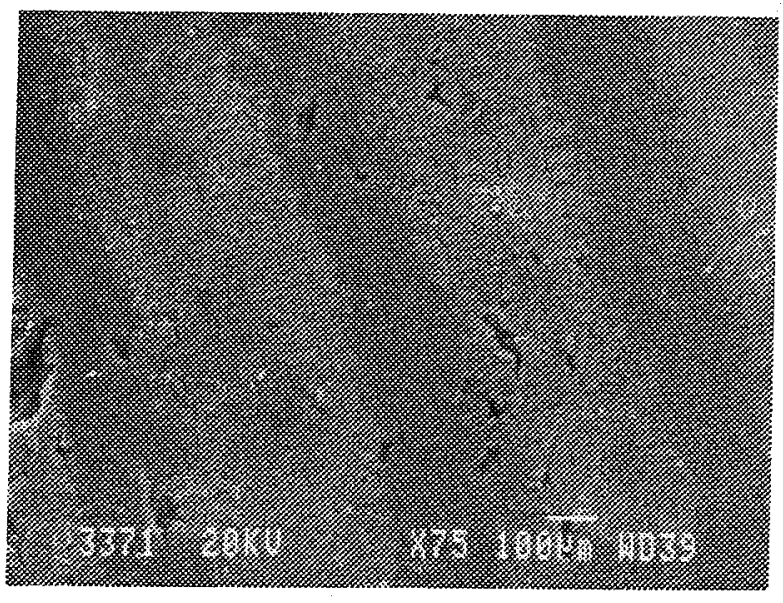

Fig. 17. B38c; highest $E_{\mathrm{t}}=2.82 \mathrm{MJ} \mathrm{m}^{-2} ; d=4 \mu \mathrm{m}$; partly eroded and cracks.

rate $\left(\left\{\mathrm{CH}_{4}\right\}=0.2\right.$ standard $\left.\mathrm{cm}^{3} \mathrm{~s}^{-1}\right)$ only a very low part of the actual arc capacity is used. For a:C-H we obtain $F \approx 1$.

\subsection{Qualitative study of thermal shock damage}

In a second heat shock test sequence the best erosionresistant coatings were subjected to a $3 \mathrm{MJ} \mathrm{m}^{-2}$ (in $10 \mathrm{~ms}$ ) thermal shock. Erosion depths were measured with a light microscope by focusing on the highest and lowest points of the erosion crater respectively. The light microscope is equipped with a nonius, so the depth can be measured in micrometers. However, this method is not accurate and the error may be tens of per cents. SEM analysis yields more detailed information of the surface damage of the coatings. The most interesting results of tests of the CG coatings are given in Figs. 17-19. The structure of all these coatings is well represented by the typical foliate structure shown in Fig. 8, with only minor variations. In Fig. 17 a micrograph of the thin coating of substrate B38c, with the highest erosion threshold is shown. The Raman spectrum of this sample is not available, but the spectrum of B38St out of the same batch (see Fig. 10(d)) indicates a highly crystalline material. It can be observed that on thermal 


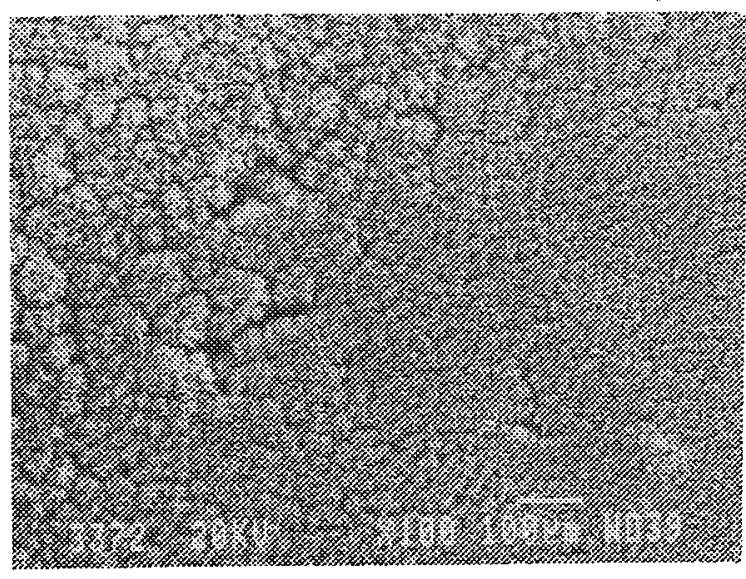

Fig. 18. B57c; "recirculation" trial; $d=57 \mu \mathrm{m}$; lowest $E_{\mathrm{d}}=32 \mu \mathrm{m}$; layer modification.

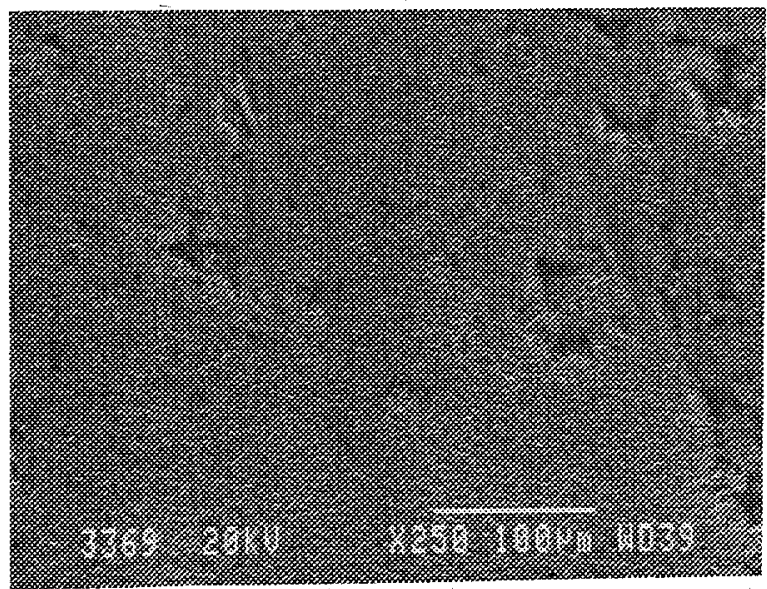

Fig. 19. B47; lowest $I_{\mathrm{d}} / I_{\mathrm{g}}=0.16$ on $\mathrm{CFC}$; crystalline optimum; $d=39 \mu \mathrm{m}$; partly eroded, small cracks.

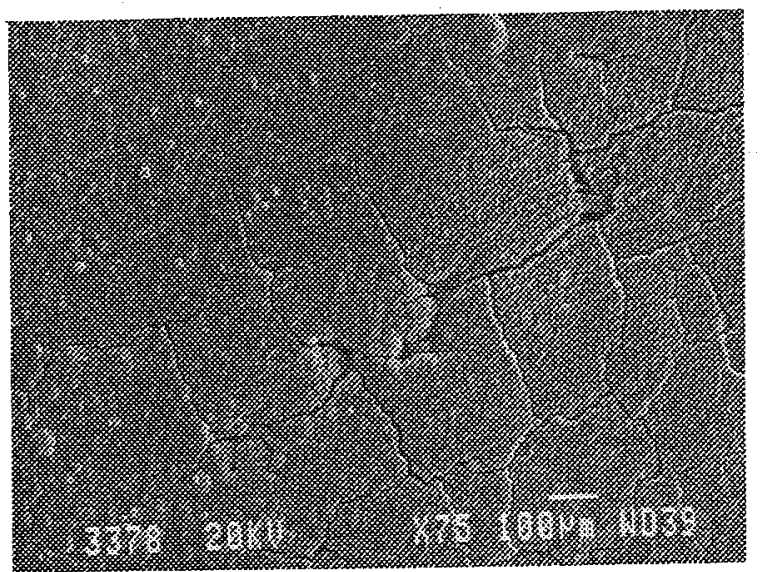

Fig. 20. B34; bias-261 V d.c.; $d=43 \mu \mathrm{m} ; R_{\mathrm{d}}=83 \mathrm{~nm} \mathrm{~s}^{-1}$; high $E_{\mathrm{t}}=1.68 \mathrm{MJ} \mathrm{m}^{-2}$; eroded and large cracks.

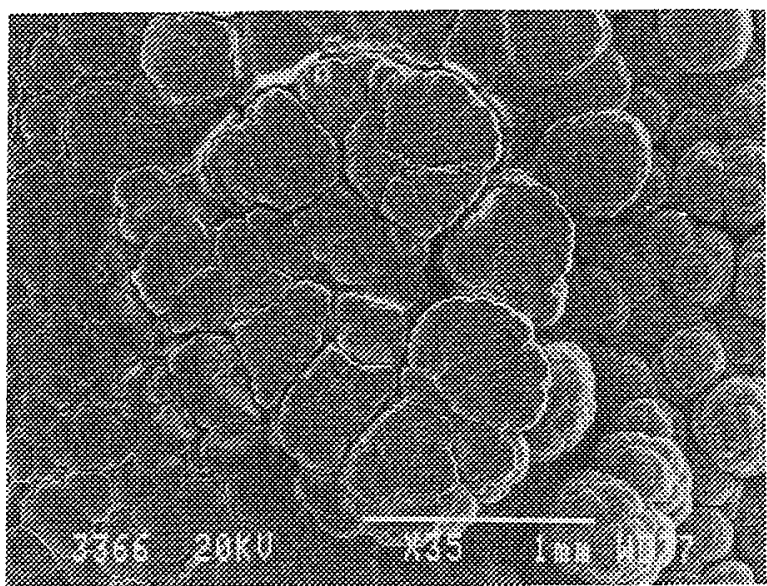

Fig. 21. B39c; $d=377 \mu \mathrm{m} ;$ high $R_{\mathrm{d}}=314 \mathrm{~nm} \mathrm{~s}^{-1}$; high $E_{\mathrm{t}}=$ $1.68 \mathrm{MJ} \mathrm{m}^{-2}$; eroded depth $145 \mu \mathrm{m}$; flattened cauliflowers.

shock testing the layer remains in place but has been partly eroded. In the residue cracks protruding in the CFC substrate are present. In Fig. 18 the result for the specific batch B57 (the "recirculation trial") is shown. B57c appeared to have the smallest erosion depth. It can be noted that the layer has remained in situ. The foliates have changed in structure somewhat, but are still clearly observable. The loss of thickness can be explained by erosion, but also by layer modification due to a kind of annealing effect. In Fig. 19 the micrograph for the interesting trial of B47 is shown. This coating is highly crystalline Table 1 . Under the $3 \mathrm{MJ} \mathrm{m}^{-2}$ thermal shock the layer suffered by erosion but remained largely intact. As for trial B57, some modification of the foliate structure has occurred.

In Figs. 20 and 21 the micrographs of two typical AG coatings after thermal shock testing are shown: B34 and B39c. Both had a rather high $E_{\mathrm{t}}$ of $1.68 \mathrm{MJ} \mathrm{m}^{-2}$ and were produced at high growth rates Table 1. Upon thermal shock testing they appear to remain in situ. The former shows extensive cracks, while the latter suffers by erosion, resulting in a crater of flattened cauliflowers.

\subsection{Diamond conditions}

When applying hydrogen admixtures suitable for diamond deposition on silicon [3] onto CFC substrates, etching becomes predominant. Only in one trial on the center CFC substrate was a small peak of CG deposited. On the accompanying steel substrate diamond was formed. Images of these deposits are shown in Figs. 22 and 23. In Fig. 22 it can be observed that underneath the diamond crystals an amorphous carbon sublayer has first been formed on the steel. As direct diamond formation on steel is theoretically impossible, this has been a necessary condition. The influence of the substrate type in the deposition process is once more stressed. The present finding is in agreement with the 


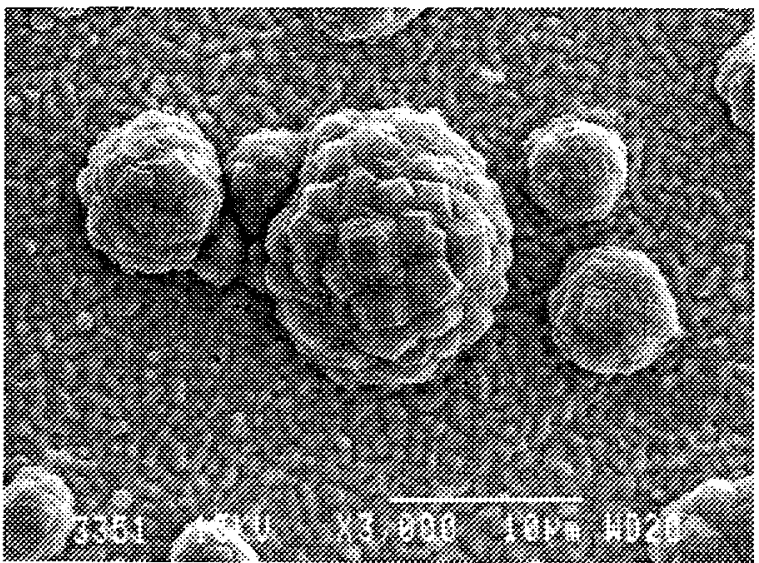

Fig. 22. SEM image of diamond (precursor) deposited onto steel, top view, B45: $\left\{\mathrm{C}_{2} \mathrm{H}_{2}\right\}=3 / 8 ;\left\{\mathrm{H}_{2}\right\}=37.5 ;[\mathrm{H}] /[\mathrm{C}]=101 ; T_{\mathrm{py}} \approx 810^{\circ} \mathrm{C}$; $p_{\mathrm{c}}=6.0 \times 10^{3} \mathrm{~Pa} ; P_{\mathrm{arc}}=3.19 \mathrm{~kW} ; \quad Q=2.3 \times 10^{-6} \mathrm{~W}^{-1} ; \quad d \approx 7 \mu \mathrm{m} ;$ $R_{\mathrm{d}} \approx 2.0 \mathrm{~nm} \mathrm{~s}^{-1}$.

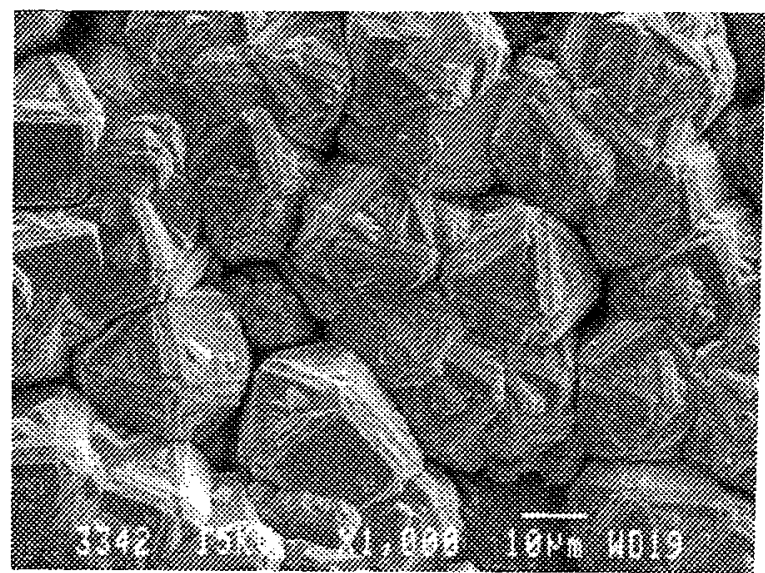

Fig. 23. SEM image of diamond film deposited onto steel, top view, B49: $\left\{\mathrm{C}_{2} \mathrm{H}_{2}\right\}=0.25 ;\left\{\mathrm{H}_{2}\right\}=50 ;[\mathrm{H}] /[\mathrm{C}]=201 ; T_{\text {py }} \approx 900^{\circ} \mathrm{C}$; $p_{\mathrm{c}}=6.4 \times 10^{3} \mathrm{~Pa} ; P_{\mathrm{arc}}=4.17 \mathrm{~kW} ; Q=1.2 \times 10^{-6} ; d \approx 17 \mu \mathrm{m} ; R_{\mathrm{d}} \approx$ $4.7 \mathrm{~nm} \mathrm{~s}^{-1}$.

assumption [26] that diamond deposition onto graphite is impossible. Recently, however, Angus has reported the growth of diamond on graphite [27].

\section{Conclusions}

(1) A diverse range of films from amorphous to highly crystalline graphite was deposited. Amorphous graphite shows a typical cauliflower structure. In crystalline graphite distinct foliates with dimensions of several micrometers can be observed. The Raman spectrum of the most crystalline materials is comparable with that of the substrate CFC, i.e. of conventional CVD pyrolytic graphite. For the deposition of crystalline materials the addition of an etching medium such as hydrogen is essential. Growth rates were on the order of hundreds of nanometers per second for the amorphous graphites and tens of nanometers per second for the crystalline graphites, both on areas of several square centimeters.

(2) For application as a plasma-facing material, processing of the coating material still needs improvement. Upon laser thermal shock tests the best crystalline coatings have an acceptable erosion threshold of about $2 \mathrm{MJ} \mathrm{m}^{-2}$ (in $10 \mathrm{~ms}$ ). Of the amorphous coatings only one (B39) showed reasonable thermomechanical behavior, with a threshold of $1.7 \mathrm{MJ} \mathrm{m}^{-2}$. This coating could be produced with an adequate growth rate of hundreds of nanometers per second. Under the $3 \mathrm{MJ} \mathrm{m}^{-2}$ pulse most coatings suffered from substantial damage. The adhesion of most coatings to the CFC substrates is good, to steel it is poor. The mechanical strength of the material is moderate. It is porous. This may be an advantage in resisting heat shocks as it may prevent cracking. In view of tritium retention it is an undesired property.

(3) Relations between deposited material and the deposition conditions were found. The three diagnostics SEM, Raman spectroscopy and laser thermal shock testing give consistent results: hydrogen addition, growth rate and possibly the $Q$ factor play a major role in determining the quality of the graphite. The correlation between the results of the diagnostics implies that SEM and Raman spectroscopy are suitable and fast methods to obtain a prediction of the coating quality, and in particular its thermomechanical qualities.

(4) The type of substrate is a principal factor in the deposition process. It appeared that the general condition of a large hydrogen admixture (to obtain a hydrogen-free crystalline layer), on CFC results in etching. With the hydrogen concentrations necessary for the deposition of pure diamond (on silicon [3]), crystalline graphite was deposited onto the center CFC substrate. On a steel substrate diamond was deposited onto an amorphous sublayer, once more indicating the influence of the substrate.

Concerning optimization of the deposition process, recent investigations indicate that with the use of another etching medium, e.g. oxygen, crystalline materials can be produced at much higher growth rates [28]. An issue is to verify that no incorporation of oxygen in the layer occurs.

The best coatings appear to have been produced with the aid of a recirculation cup (B57). Also, coating with oblique incidence of the beam (B56) gave a good result, as well as coating with bias (B34). Optimization of other aspects of the deposition technique, such as substrate geometry, is promising.

The optimum between (volume) growth rate and crystallinity is most probably not yet reached. At present, it is approximated best by the conditions of B47. It is expected that with independent control of the various 
reactor parameters, e.g. substrate temperature and nozzle to sample distance, the results can still be improved.

\section{Acknowledgments}

This paper reports the main results of the NET Garching-ECN Petten-TU Eindhoven research agreement Investigation of Plasma-deposited Carbon Films as Possible Means of Divertor Repair, as established in the NET contract 90-237 between The European Atomic Energy Community and Euratom/FOM Association. It is funded by the Commission of the European Communities, which is representing the Ëuropean Atomic Energy Community.

The authors would like to thank M. J. F. van de Sande for solid technical support, and G. M Janssen and M. C. M. van der Sanden for computational support. Further the authors would like to thank Dr. D. J. Stufkens and Mr. T. L. Snoeck of the University of Amsterdam for measuring the Raman spectra.

\section{References}

1 R. D. Watson (ed.), ITER divertor engineering design, ITER-TNPC-8-9-1, October 1989 (Max-Planck-Institut für Plasmaphysik, Garching).

2 G. M. W. Kroesen, D. C. Schram and M. J. F. van de Sande, Plasma Chem. Plasma Process, 10 (1990), 1, 49.

3 P. K. Bachmann, H. Lydtin, D. U. Wiechert, J. J. Beulens, G. M. W. Kroesen and D. C. Schram, in T. S. Sudarshan and D. G. Bhat (eds.), Surface Modification Technologies III, The Minerals, Metals and Materials Society, Warrendale, PA, 1990, p. 69.

4 A. J. M. Buuron, J. J. Beulens, M. J. F. van de Sande and D. C. Schram, Fusion Technol., 19 (1991) 2049.

5 J. G. van der Laan, H. T. Klippel, R. C. L. van der Stad and J. Bakker, Fusion Technol., 19 (1991) 2070.

6 T. Kuroda and G. Vieider (eds.), ITER Plasma Facing Components, ITER Documentation Series, 30, International Atomic Energy Agency, Vienna, 1990.

7 M. C. M. van der Sanden, Ph.D. Thesis, Eindhoven University of Technology, November 1991.
8 G. M. W. Kroesen, D. C. Schram, A. T. M. Wilbers and G. J. Meeusen, Contrib. Plasma Phys., 31 (1991) 1, 27.

9 J. J. Beulens, M. de Graaf, G. M. W. Kroesen and D. C. Schram, in D. Apelian and J. Szekely (eds.), Proc. Materials Research Society Spring Meet., San Francisco, CA, April 1990, Materials Research Society Pittsburgh, PA, 1991, A331.

10 D. L. Smith, R. E. Nygren, P. Gorenson (US ITER Team) U.S. Technical Report for the ITER Plasma Facing Components, ITERTN-PC-1-0-4-2, Max-Planck-Institut für Plasmaphysik, Garching, June 1990.

11 W. Zhu, C. A. Randall, A. R. Badzian and R. Messier, J. Vac. Sci. Technol. A, 7 (3) (1989) 2315.

12 Y. Mitsuda, Y. Kojima, T. Yoshida and K. Akashi, J. Mater Sci., 22 (1987) 1557.

13 J. G. van der Laan (Garching NET team), J. Bakker (Petten ECN), private communication, 1990.

14 J. G. van der Laan, J. Bakker, R. C. L. van der Stad and H. T. Klippel, Proc. 16th Symp. on Fusion Technology, London, September 3-7, 1990, Elsevier, Amsterdam, 1991, p. 438.

15 J. G. van der Laan, H. T. Klippel, J. Bakker and R. C. L. van der Stad, Proc. 4th Int. Conf. on Fusion Reactor Materials, Kyoto, Japan, '1989, in J. Nucl. Mater., 179-181 (1990) 270.

16 R. Messier and J. E. Yehoda, J. Appl. Phys. 58, (10) (1985) 3739 .

17 J. Robertson, Adv. Phys., 35 (4) (1986) 317.

18 N. B. Brandt, S. M. Chudinov and Ya. G. Ponomarev, Semimetals, Vol. 1, Graphite and its Compounds, North-Holland, Amsterdam, 1988, p. 355.

19 G. M. Janssen, Master's Thesis Eindhoven University of Technology, June 1991.

20 R. J. Nemanich and S. A. Solin, Phys. Rev. B, 20 (1979) 392.

21 F. Tuinstra and J. L. König, J. Chem. Phys., 53 (1970) 1126.

$22 \mathrm{~K}$. Niwase, K. Nakamura, I. Tanaka, Y. Miyamoto and T. Tanabe, Proc. 4th Int. Conf. on Fusion Reactor Materials, Kyoto, Japan, 1989, in J. Nucl. Mater., 179-181 (1990) 214.

$23 \mathrm{~K}$. Ashida, K. Kanamori and K. Watanabe, J. Vac. Sci. Technol., A, 6 (4) (1989) 2232.

24 P. L. Walker and P. A. Thrower (eds.), Chemistry and Physics of Carbon: A Series of Advances, Vol. 11, Marcel Dekker, New York, 1974.

25 A. Staudinger and S. Nakahara, Thin Solid Films, 45 (1977) 125.

26 S. P. Chauhan, J. C. Angus and N. C. Gardner, J. Appl. Phys., 47 (11) (1976) 4746

27 J. C. Angus, Proc. 2nd Int. Conf. on Diamond, Diamond-like and Related Materials, Nice, September 2-6, 1991, in Diamond Related Mater., in the press.

28 D. C. Schram and J. J. Beulens, Eindhoven University of Technology, Department of Physics, private communication, 1991. 